\title{
Organic Letters
}

Supplementary Information for

Conformationally Imprinted Receptors: Atropisomers with 'Write', 'Save' and 'Erase' Recognition Properties

Authors:

Charles F. Degenhardt III, Judith M. Lavin, Mark D. Smith Ken D. Shimizu*

Department of Chemistry and Biochemistry, University of South Carolina, Columbia, SC 29208 Fax: (803)777-9521; Tel: (803)777-6523

E-mail:shimizu@mail.chem.sc.edu 


\section{1) General Experimental:}

NMR spectra were recorded on a Varian $300 \mathrm{MHz}$ spectrometer. Chemical shifts are reported in ppm $(\delta)$ referenced to TMS $(\delta 0.00 \mathrm{ppm})$ in ${ }^{1} \mathrm{H}$ NMR. All chemicals were purchased from commercial suppliers and used as received unless otherwise specified. Diacid 1 was synthesized and the syn- and anti-atropisomers were separated and isolated by column chromatography as previously described. ${ }^{1}$ Flash chromatography was performed using silica (Sorbent Technologies, silica gel $60 \AA$, 200-400 mesh). HPLC was performed using a Varian Prostar HPLC model 210 equipped with a Varian Prostar UV-Vis detector model 320, and a Rainin Dynamax $60 \AA$ silica column. UV detection was performed at $254 \mathrm{~nm}$.

\section{2) Ethyl adenine-9-acetate and Syn Diacid Co-crystallization:}

An equimolar ratio of syn-diacid $\mathbf{1}$ and EA9A in acetonitrile was slowly evaporated from a septum covered test tube containing a ventilation needle. Crystals appeared in 4-7 days.

\section{3) Titration Study:}

Aliquots of the diacid $1(3 \mathrm{mM})$ in $\mathrm{CD}_{3} \mathrm{CN}$ were added to a $600 \mu \mathrm{L} 1 \mathrm{mM}$ solution of EA9A in $\mathrm{CD}_{3} \mathrm{CN}$. A spectrum was taken after each addition of diacid $\mathbf{1}$ and the EA9A amine protons were followed.

\section{4) Control Studies:}


Solutions were of anti-1 $(5 \mathrm{mM})$ and $20 \mathrm{mM}$ of either 1,4diazabicyclo[2.2.2] octane (DABCO) or $N$-acyl-2-aminopyridine. The solutions were transferred to NMR tubes, and each was heated at $90{ }^{\circ} \mathrm{C}$ for $21 \mathrm{~h}$. The resulting ratio of syn- and anti-1 was monitored by HPLC (Rainin Dynamax $60 \AA$ silica gel column with $35 \% \mathrm{HOAc}$ and $65 \% \mathrm{CHCl}_{3}$ as the mobile phase at a flow rate of $1.0 \mathrm{~mL} / \mathrm{min}$ ). A second control study was performed in which a $5 \mathrm{mM}$ solution of anti diacid was heated to $90{ }^{\circ} \mathrm{C}$ in the presence of $15 \mathrm{mM}$ EA9A in DMSO.

1 Degenhardt, C., III; Shortell, D. B.; Adams, R. D.; Shimizu, K. D. Chem. Comm. 2000, 929-930. 